\title{
SALA DE AULA INVERTIDA NO ENSINO DA QUÍMICA ORGÂNICA: UM ESTUDO DE CASO
}

\author{
Bruna R. F. da Silva ${ }^{a}$, Sebastião L. da Silva Neto e Bruno S. Leite ${ }^{\mathrm{b}, *,(1)}$ \\ anidade Acadêmica de Serra Talhada, Universidade Federal Rural de Pernambuco, 56909-535 Serra Talhada - PE, Brasil

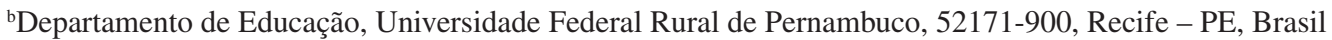

Recebido em 09/07/2020; aceito em 20/10/2020; publicado na web em 26/11/2020

\begin{abstract}
FLIPPED CLASSROOM IN TEACHING ORGANIC CHEMISTRY: A CASE STUDY. The flipped classroom is one of the types of rotation model strategies that aim of increasing interaction and personalized contact time between students and teachers in the classroom setting. In this study, we investigated the application of the flipped classroom strategy in two classes of the different semesters in the discipline of Organic Chemistry. The teacher applied this strategy in different ways in order to verify how the flipped classroom can contribute to the teaching and learning process in the content of Nuclear Magnetic Resonance (NMR). The research, of qualitative nature, is a case study being carried out in six steps with the participation of twenty-five students and one teacher. The instruments used for data collection were an investigative questionnaire (applied to students) and a structured interview (carried out with the teacher). The results show that the students had control over their learning, presenting a favorable position for the application of the strategy. In addition, the teacher reported that it was possible to deepen the content of NMR with his students, teaching the class in a different way than he was used to, focusing on doubts (individual and collective), as well as comments regarding the materials produced by him.
\end{abstract}

Keywords: flipped classroom; teaching organic chemistry; digital technologies; blended learning; NMR.

\section{INTRODUÇÃO}

$\mathrm{Na}$ sociedade é muito comum estarmos envolvidos com as tecnologias digitais de informação e comunicação (TDIC), pode ser no uso de uma TV, do rádio ou de um celular. A humanidade faz uso de recursos tecnológicos desde os primórdios e através do aperfeiçoamento dos conhecimentos as pessoas podem usufruir as mais avançadas tecnologias em praticamente todos os ambientes de suas vidas. Nesse sentido, no ambiente educacional, o uso das tecnologias digitais pode acentuar o processo de ensino e aprendizagem, isso é, dando autonomia a escola para oferecer meios em que os estudantes tenham acesso as TDIC e que esses façam uso delas. Contudo, para isso acontecer é necessário que os professores tenham o devido preparo para fazer uso das tecnologias em sala de aula, em especial das tecnologias digitais (concordamos com as ideias de Leite, ${ }^{1}$ sobre a diferença entre os termos tecnologias e tecnologias digitais), uma vez que somente disponibilizar as ferramentas em sala de aula não permite com que sejam dadas oportunidades de um maior aprendizado para o estudante. De acordo com Goudouris e Struchiner ${ }^{2}$ os recursos digitais

podem ser úteis, oferecendo conteúdo a ser estudado, bem como promovendo a comunicação entre professores e alunos em horário e lugar de conveniência de cada um, ou seja, permitindo simultaneamente estudo independente e comunicação assíncrona, respeitando a individualidade e a disponibilidade dos envolvidos ${ }^{2}$ (p. 621).

Conciliar o processo de ensino e aprendizagem com as tecnologias digitais disponíveis se faz necessário, uma vez que estimula um melhor desempenho e desenvolvimento do saber e conhecer por parte do estudante. ${ }^{3}$ Atualmente, percebe-se que grande parte da população mundial esteja ativamente conectada as tecnologias digitais, principalmente no que se refere aos dispositivos móveis,

*e-mail: brunoleite@ufrpe.br que são de fácil uso e bem acessíveis. Tendo em vista que os âmbitos sociais e culturais estão intimamente relacionados às tecnologias, observa-se que com a educação não poderia ser diferente. Todavia, para muitos dos profissionais da educação um dos principais desafios é saber como aliar as tecnologias ao ensino de forma que haja um processo de interação e colaboração entre os estudantes e o professor. Considerando que a globalização é um processo em crescente desenvolvimento, caberá ao professor se qualificar e estar atento às várias formas disponíveis de metodologias em que a tecnologia pode auxiliar, fazendo uso dela para que ajude seus estudantes a se sentirem comprometidos com sua aprendizagem. ${ }^{4}$ Ao compreender as TDIC como recursos importantes na aprendizagem do século XXI, o professor irá não somente fazer sua aula se tornar mais dinâmica e atraente, mas irá aproximá-la da realidade de seus estudantes, em que as informações estão circulando a todo instante.

Nesse contexto, observamos a inserção do ensino virtual, que pode ocorrer por meio da modalidade de ensino on-line em que toda a instrução é realizada via internet, cuja comunicação ocorre de forma síncrona ou assíncrona, ou pela modalidade de Ensino a Distância (EaD), na qual os estudantes têm encontros com os professores de forma on-line para assistirem as aulas independentemente de onde se encontram, o espaço e o tempo é de livre escolha do discente, diferentemente do ensino presencial em que todos os estudantes devem estar no mesmo local e ao mesmo tempo para assistirem as aulas. Segundo Leite, ${ }^{5}$ uma terceira forma de ensino tem surgido da junção do ensino virtual com o ensino presencial, conhecido como Ensino Híbrido (blended learning). O ensino híbrido é "considerado qualquer programa educacional formal no qual um estudante constrói sua aprendizagem, pelo menos uma parte, por meio do ensino on-line em que o mesmo tenha controle de algum elemento (tempo, lugar ou ritmo)"5 (p.212). É uma prática pedagógica que utiliza recursos digitais em sala de aula, em outras palavras, é a implementação da tecnologia no ensino como estratégia para desenvolver melhor a aprendizagem dos estudantes. Entende-se por híbrido algo misto, e o ensino é híbrido porque não aprendemos somente no ambiente escolar, mas em qualquer local, e 
porque não se reduz ao que planejamos institucionalmente, intencionalmente. Aprendemos através de processos organizados, junto com processos abertos, informais. Aprendemos quando estamos com um professor e aprendemos sozinhos, com colegas, com desconhecidos. Aprendemos intencionalmente e aprendemos espontaneamente ${ }^{6}(\mathrm{p} .45)$.

Neste modelo de ensino o professor deixa de ser o único detentor do conhecimento e centro do aprendizado para ser um mediador, ${ }^{1,4}$ pois o estudante é quem está no centro do processo de construção do conhecimento. Conforme destaca Moran, ${ }^{7}$ as metodologias ativas possibilitam ao estudante o papel de protagonista considerando " [...] seu envolvimento direto, participativo e reflexivo em todas as etapas do $\operatorname{processo"~}^{\text {" }}$ (p. 4). Em outras palavras, coloca o estudante no centro do processo de ensino e aprendizagem, procurando envolvêlo ativamente, descentralizando o papel do professor, que se torna um mediador/facilitador para que a informação repassada seja transformada em conhecimento. ${ }^{4,8}$

Neste contexto, esta pesquisa teve como objetivo investigar a aplicação da estratégia da sala de aula invertida (SAI) em duas turmas de semestres diferentes na disciplina de Química Orgânica da Universidade Federal Rural de Pernambuco (UFRPE) no curso de licenciatura em Química na unidade acadêmica de Serra Talhada. A aplicação desta estratégia pelo professor foi realizada de formas distintas de modo a verificar como a SAI pode contribuir no processo de ensino e aprendizagem nas aulas de Química Orgânica.

\section{ENSINO HÍBRIDO}

O ensinar e aprender atualmente tem ocorrido numa interligação simbiótica, intensa, constante entre o mundo físico e mundo digital. Não são dois espaços distintos, mas um espaço estendido, um ambiente denominado de híbrido. Nesse ambiente, a construção do conhecimento ocorre não apenas no espaço físico da sala de aula (da escola), mas nos múltiplos espaços do cotidiano, que incluem o espaço digital. ${ }^{9}$ Além disso, o tempo para a interação com o conteúdo é variável, e o tempo para a compreensão do conteúdo a ser ministrado em sala de aula com a mediação do professor seria fixo. Em sala de aula, o professor faz uso de diversas atividades que estimulem o pensamento crítico, que faça com que os estudantes sejam confrontados com problemas que exijam debates, especulação de possíveis soluções etc. e essas atividades propostas são caracterizadas como metodologias ativas, em que o modelo do ensino híbrido pode apresentar características dessas metodologias.

Há várias metodologias que podem ser utilizadas em sala de aula para auxiliarem na aprendizagem, mas nem todas envolvem o estudante como protagonista de seu próprio conhecimento. Nessa perspectiva, consideramos importante o modelo da aprendizagem tecnológica ativa (ATA) que discute sobre cinco pilares (papel do professor, protagonismo do aluno, uso das tecnologias, aprendizagem e avaliação) fundamentais para uma aprendizagem mais ativa através do uso das tecnologias digitais. ${ }^{4} \mathrm{Na}$ ATA, o professor faz uso de aparatos tecnológicos para melhorar a forma como estrutura sua aula, além de promover uma maior capacidade de seus estudantes em serem autônomos em relação ao que estudam. A aplicação da ATA pode ocorrer de diversos modos na educação e são inúmeras as metodologias ativas que podem ser abordadas. ${ }^{1}$

O Ensino Híbrido $(\mathrm{EH})$ é um modelo de ensino que envolve a utilização das tecnologias na educação, em que as mesmas são integradas de forma inerente as aulas para auxiliar os professores na forma como ministram as aulas e também auxiliar os estudantes na forma como aprendem, uma vez que ao se fazer uso dessa metodologia o professor delega ao estudante o compromisso com a sua própria aprendizagem (característica presente na ATA - protagonismo do estudante). O estudante passa a ser o centro no processo de aprendizagem e o professor se torna o mediador/orientador na construção de conhecimento do estudante. Através de diferentes situações os estudantes conseguem ter possibilidades distintas de resolverem o problema, criando assim uma forma autônoma de interagir com o objeto em estudo, além de estarem intimamente relacionados com o que estão aprendendo. Dessa maneira, abrese a oportunidade de o estudante ter iniciativa de buscar opções, alternativas de aprender em sala de aula, principalmente a expor suas opiniões e debatê-las com o professor.

Uma das características do EH é ser derivado do ensino virtual e do ensino presencial, por isso ele pode ser dito como um "ensino misturado", em que tanto o estudante quanto o professor estão ativamente em contato não importando mais o tempo ou o espaço. $\mathrm{O}$ EH possui quatro modelos que podem ser utilizados pelos professores:

1. Rotação;

2. Flex;

3. À la carte;

4. Virtual enriquecido.

Sendo que estes três últimos (Flex, à la carte e virtual enriquecido) são considerados disruptivos, uma vez que eles alteram o que se "normalmente" tem sido realizado nos ambientes educacionais, como é explicitado por Castro e Mill, ${ }^{10}$ esses modelos "não incluem a sala de aula tradicional em sua forma plena; apenas mostram o benefício desta sala, de acordo com uma nova definição do que é bom"10 (p.764). Já Horn, Staker e Christensen ${ }^{11}$ destacam que esses modelos são uma passagem para uma inovação disruptiva mais permanente na educação.

Destes modelos de EH, o Rotacional (Rotação) é o mais utilizado nas pesquisas envolvendo o $\mathrm{EH}$, por ser mais flexível em relação as suas estratégias e é compreendido basicamente como sendo um conjunto de atividades selecionadas e orientadas pelo professor para os estudantes. Ele possui quatro estratégias que estão disponíveis para uso do professor, que são elas:

1. Sala de Aula Invertida (SAI);

2. Rotação por estações;

3. Rotação Individual;

4. Laboratório Rotacional.

A sala de aula invertida, como o próprio nome indica, invertese a dinâmica das aulas no sentido de que a aula presencial não é mais aquela em que o estudante irá sentar e assistir uma exposição de conteúdo. Na SAI o estudante irá ser orientado pelo professor com relação ao conteúdo que será ministrado. Esta estratégia possui duas etapas: (1) uma virtual, em que o professor irá selecionar o conteúdo e compartilhar com a turma por alguma plataforma on-line (por exemplo, Google Sala de Aula, E-mail, Whatsapp etc.) de sua preferência, em que os estudantes vão estudar o conteúdo da aula, tendo como base o material fornecido pelo professor. Todavia, os estudantes podem fazer uso de outros materiais para obterem mais informações; (2) uma presencial, em que o estudante que já teve contato com o conteúdo e o estudou, vem para sala de aula debater com os colegas e com o professor sobre o que foi estudado, assim o professor irá contribuir com sua experiência e aprofundar o conteúdo, além de sanar as dúvidas que surgiram durante o estudo do conteúdo.

Destarte, o ensino híbrido possibilita a identificação de um problema aliado a um projeto para a solução, uma vez que um dos desafios dos professores é flexibilizar suas aulas e ao mesmo tempo acompanhar a evolução e o desempenho de cada estudante. Outro ponto observado no EH é a personalização do ensino, em que o estudante e o professor irão ter contato mútuo com a tecnologia, fazendo uso da mesma de forma que atenda às necessidades de ambos. 
Entende-se que o professor ao se aperfeiçoar com essas tecnologias, e fazendo uso destas, poderá promover uma melhoria dentro de sala de aula, ${ }^{5}$ pois os recursos didáticos digitais $(\mathrm{RDD})^{3}$ possibilitam que os estudantes tenham controle sobre sua aprendizagem. Ademais, os estudantes não são tão impactados com a mudança das práticas pedagógicas adotadas pelo professor nesse contexto, já que estão acostumados em sua rotina a utilizarem as tecnologias digitais, uma vez que o "professor precisa seguir comunicando-se face a face com os alunos, mas também digitalmente, com as tecnologias móveis, equilibrando a interação com todos e com cada um"12 (p.57).

Ao utilizar os ambientes virtuais, o professor vai ter mais tempo para fazer com que o estudante tenha contato com o conteúdo de forma mais abrangente, sendo amparado por maiores meios de aprendizagem, além de contar com a orientação constante do professor. A sala de aula, ao se transformar em um espaço de debates, proporciona discussões acerca do que foi significativo para o estudante, obtendo um maior aprofundamento, auxiliando cada estudante na construção do seu conhecimento e promovendo uma maior autonomia, mostrando que o conhecimento é algo que pode se dar de forma dinâmica e interativa.

\section{METODOLOGIA}

A pesquisa segue os moldes de natureza qualitativa na qual se obtêm dados a partir da observação, entrevistas ou interações verbais e foco nas intenções dos participantes,${ }^{13}$ com o objetivo de interpretar os dados referentes ao objeto em estudo. ${ }^{14}$ Além disso, trata-se de um estudo de caso, pois compreende uma investigação sobre algo que tenha valor em $\mathrm{si}^{15}{ }^{15}$ que entendemos ser a estratégia da SAI, de modo a analisar as percepções dos estudantes do ensino superior ao utilizarem este modelo rotacional do Ensino Híbrido e como ela auxiliou o professor em sua prática pedagógica.

A estratégia da SAI foi realizada nos dois ambientes (virtual e presencial) e aplicada em duas turmas do Curso de Licenciatura em Química da UFRPE na disciplina de Química Orgânica C. Para isso a pesquisa foi realizada em seis etapas (Figura 1) descritas a seguir.

$\checkmark$ Etapa 1: Escolha do conteúdo a ser abordado na disciplina de Química Orgânica C (ofertada no $7^{\circ}$ período do curso). A disciplina escolhida para realizar a aplicação da SAI apresenta uma diversidade de conteúdos e o professor responsável em ministrar a disciplina analisou o grau de dificuldade que os estudantes poderiam ter entre os assuntos que seriam ministrados. A seleção do conteúdo foi de livre escolha do docente responsável pela disciplina. Assim, optouse pelo conteúdo de RMN (Ressonância Magnética Nuclear), sendo justificado pelo docente por considerá-lo o melhor conteúdo a ser visto de forma mais dinâmica pelos alunos, uma vez que o mesmo trata de análises de espectros, o que se tornaria bastante interessante mostrá-los com apoio dos RDD;

$\checkmark$ Etapa 2: Elaboração do material digital para a realização da SAI. Após a definição do conteúdo a ser trabalhado com as turmas, o docente optou pela utilização de um vídeo que contivesse animações, textos, explicações do docente e outras estratégias que facilitassem a compreensão dos estudantes. O vídeo foi elaborado pelo professor e nele há explicações de parte do conteúdo de RMN. Cabe destacar a opção do docente em inserir no vídeo dois áudios que representavam o sinal que o aparelho de RMN emite, tendo como finalidade uma melhor compreensão dos estudantes em relação ao aparelho, fazendo ligação entre a teoria e a prática do conteúdo. Além do vídeo, foi elaborada uma apresentação em slide pelo docente sobre RMN, com o objetivo dos estudantes a utilizarem após assistirem ao vídeo. A apresentação destaca textos e imagens consideradas "chaves" pelo docente para a compreensão do conteúdo complementando o conteúdo do vídeo. Artigos de revistas científicas sobre RMN foram selecionados pelo docente com o intuito de disponibilizá-los para os discentes. Por fim, o docente elaborou uma lista de exercícios sobre o conteúdo para contribuir no processo de construção de conhecimento dos estudantes;

$\checkmark$ Etapa 3: Disponibilização do material digital para os estudantes (Realização da SAI - $1^{\text {a }}$ parte). Consistindo no momento virtual da SAI, o professor disponibilizou o vídeo para os alunos através de uma plataforma digital (escolhida pelo docente). Os estudantes tiveram acesso a um link privado para assistirem ao vídeo. Além disso, a plataforma permitia que os discentes interagissem com o professor e com os demais estudantes através de comentários que ficavam disponibilizados no próprio ambiente que o vídeo estava disponível. Nessa plataforma também foram disponibilizados a apresentação em slide, os artigos e a lista de exercícios para que os estudantes, logo após assistirem ao vídeo, pudessem ter acesso a outros recursos. $\mathrm{O}$ docente explicitou para os estudantes que estaria disponível on-line (por meio de chat, e-mail, redes sociais) para ajudar e orientá-los caso tivessem com algum tipo de dificuldade. Ele também incentivou os estudantes a buscarem outros materiais (em sites, livros etc.) para auxiliar na compreensão do conteúdo, incentivando-os a buscarem de forma autônoma e livre (considerando os pressupostos da ATA). ${ }^{1,4}$ Os discentes tiveram uma semana para assistirem ao vídeo, verem o slide, lerem os artigos e responderem a lista de exercícios, além de se comunicarem com o professor de forma on-line para tirarem dúvidas e se comunicarem com os próprios colegas de classe (atendendo uma das características da ATA);

$\checkmark$ Etapa 4: Debates sobre o conteúdo (Realização da SAI - $2^{\text {a }}$ parte). Essa etapa constou de três momentos, todos realizados presencialmente. No primeiro momento foram reservados 10

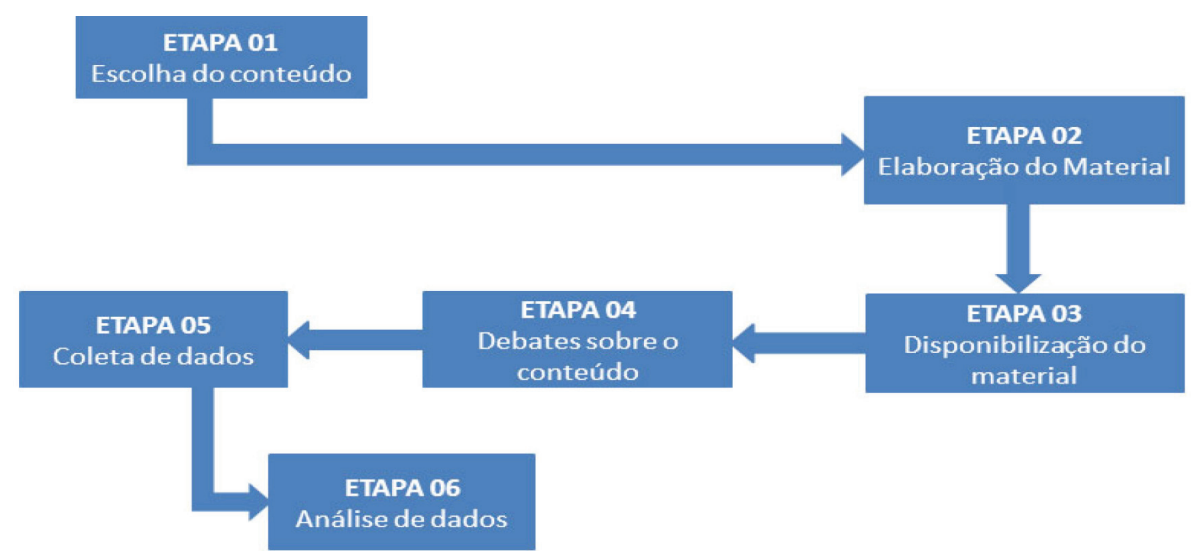

Figura 1. Fluxograma das etapas da Sala de Aula Invertida 
minutos da aula para a explanação do professor sobre o conteúdo, em seguida (segundo momento) foi realizada a discussão com os estudantes acerca da compreensão deles do assunto com o intuito de aprofundar o conhecimento sobre RMN. O tempo reservado para este momento foi de 60 minutos. No terceiro momento, o docente solicitou que os estudantes apresentassem a resolução das atividades disponibilizadas, esclarecendo possíveis dúvidas. O tempo reservado para este momento foi de 50 minutos;

$\checkmark$ Etapa 5: Coleta dos dados. Para avaliar de forma qualitativa qual foi o nível de aceitação acerca da estratégia utilizada, como instrumento de coleta de dados foi aplicado um questionário investigativo que continha treze questões objetivas e discursivas (Quadro 1).

Quadro 1. Questionário para os estudantes

1. Você conseguiu assistir ao vídeo da aula sobre RMN que foi disponibilizado pelo professor?

2. Você pôde compreender o conteúdo de RMN de uma forma clara e objetiva?

3. Você acha que essa metodologia foi boa para tratar sobre o conteúdo de RMN?

4. Você acredita que as dúvidas tiradas em sala de aula depois de assistir ao vídeo sanaram as suas dificuldades no conteúdo?

5. Você realizou alguma pesquisa para complementar a aprendizagem do conteúdo?

( ) Sim. Por que o assunto estava muito resumido.

( ) Sim. O conteúdo estava bem claro, mas sempre pesquiso algo a mais para complementar o assunto da aula.

( ) Não. Achei que o vídeo estava completo e que não teria nenhuma dificuldade para resolver as atividades.

( ) Não Todo material que o professor envia é suficiente para a aula.

6. Para você o vídeo promoveu uma facilitação no debate em sala de aula ou na realização de uma atividade?

7. Houve melhoria na dinâmica do professor ao fazer uso desse tipo de ferramenta?

8. O que você achou da estratégia de ver o conteúdo de RMN no vídeo e depois tirar dúvidas em sala de aula?

9. Você aplicaria essa estratégia em sua prática docente?

10. As Tecnologias atualmente vêm sendo bastante utilizadas em sala de aula, você acredita que elas contribuem para a explicação de todos os conteúdos vistos na química orgânica?

11. O que se deve fazer para incluir ainda mais as tecnologias (como jogos digitais, vídeos, etc.) nas aulas de Química Orgânica?

12. Com qual frequência o professor utiliza recursos didáticos digitais em sala de aula?

13. O uso das tecnologias facilita o desempenho do:

a) Professor para ensinar um conteúdo novo?

b) Aluno para aprender conteúdos novos?

O questionário investigativo foi aplicado nas turmas no dia posterior ao debate em sala com o intuito dos estudantes terem tempo suficiente para respondê-lo. O tempo reservado para que os estudantes respondessem foi de uma hora, possibilitando que estes ficassem à vontade para descreverem suas impressões com relação a SAI, críticas e ideias para melhorar a estratégia, relatando os pontos que foram positivos e negativos.

No intuito de compreender as percepções do professor da disciplina acerca da metodologia do Ensino Híbrido, em específico da SAI, foi utilizada uma entrevista estruturada (Quadro 2), constando de dez perguntas que foram gravadas em áudio e posteriormente transcritas para análise. A entrevista estruturada é um processo conduzido de acordo com um roteiro de perguntas preestabelecidas, que são aplicadas aos entrevistados de forma planejada para extrair o máximo de informações destes com um mínimo de perguntas do entrevistador. ${ }^{16}$

\section{Quadro 2. Entrevista estruturada}

1. Em sua prática como professor, como você gosta de ministrar suas aulas?

2. Como professor, até que ponto você acha que as tecnologias podem contribuir para a aprendizagem de seus alunos?

3. Ao utilizar a estratégia da Sala de Aula Invertida você acredita que auxiliou na construção do conhecimento dos alunos de orgânica? Como você avalia isso?

4. Qual das turmas você acredita que a estratégia foi mais efetiva? Por quê?

5. Na sua opinião houve variações entre as turmas com relação a utilização da sala de aula invertida?

6. Você observou alguma mudança na dinâmica ou no comportamento entre os alunos na sala de aula virtual?

7. Ao fazer uso desse método do ensino híbrido, como você avalia essa metodologia?

8. Você considera que o(s) recurso(s) didático(s) digital(is) utilizado(s) foi(ram) benéfico(s) para melhorar suas aulas

9. Qual sua avaliação geral da atividade?

10. Gostaria de sugerir ou comentar algo sobre a prática realizada?

$\checkmark$ Etapa 6: Análise dos dados. A análise é "a tentativa de evidenciar as relações existentes entre o fenômeno estudado e outros fatores" ${ }^{16}$ (p.22). Essas relações podem ser "estabelecidas em função de suas propriedades relacionais de causa-efeito, produtor-produto, de correlações, de análise de conteúdo etc." ${ }^{17}$ (p.178). Nesse sentido, a análise do questionário foi realizada a partir da leitura das respostas apresentadas pelos estudantes, descrevendo aspectos considerados pelo pesquisador como relevantes para a pesquisa. Algumas respostas foram categorizadas e agrupadas em gráficos/tabelas e descritas conforme as falas dos estudantes.

Ao total participaram vinte e cinco (25) discentes do curso de licenciatura em Química, ambos da disciplina de Química Orgânica C, sendo que 13 estudantes cursaram a disciplina no primeiro semestre de 2019 (denominada de Turma A) e 12 no segundo semestre (Turma B). Embora pareça ser um número pequeno de estudantes, este quantitativo representa o número total de estudantes da disciplina (disciplinas que são ministradas da metade para o final do curso têm menor número de estudantes quando comparamos com as disciplinas dos primeiros semestres). Cabe destacar que na Turma A, a estratégia da SAI foi aplicada na parte final da disciplina (em que os discentes estudaram diversos conteúdos da disciplina antes da discussão sobre RMN) e na Turma B foi aplicada no início das aulas da disciplina (sendo o primeiro conteúdo abordado na disciplina). De modo a assegurar o anonimato dos estudantes durante a transcrição dos textos optamos por identificá-los de acordo com suas turmas. Os estudantes da turma A serão identificados como AN (em que A significa a turma A e $\mathrm{N}$ o estudante a que se faz referência), semelhantemente com os estudantes da turma B. Ademais, tomamos o cuidado de preservar a fidedignidade dos textos produzidos pelos discentes de modo a não alterar a versão original.

Em relação à entrevista com o professor (que atuou nas duas turmas), realizou-se a transcrição da mesma e posteriormente a interpretação do seu discurso. Essa interpretação buscou 
fundamentar-se com o que se encontra atualmente na literatura a respeito de como a utilização das tecnologias digitais influenciam no processo de ensino e aprendizagem e sobre as contribuições do ensino híbrido, especialmente da SAI, no ensino de Química.

Acredita-se que os instrumentos utilizados nessa pesquisa permitem a coleta das informações, proporcionando reflexões e avaliação das ações desenvolvidas. A articulação entre o objetivo da pesquisa, a base teórica adotada e os dados coletados darão origem aos resultados e as considerações finais.

\section{RESULTADOS E DISCUSSÃO}

Ao se realizar a análise das respostas obtidas dos discentes foi observada que a maioria é favorável a estratégia da sala de aula invertida mesmo sem saber exatamente qual era a metodologia que estava sendo aplicada pelo professor em sala de aula. Essa informação mostra que independente da estratégia a ser utilizada, é possível quando se há um planejamento do docente buscar formas diferentes de práticas pedagógicas das observadas no modelo tradicional de ensino (expositivo e não dialogado) para abordar determinado conteúdo com os estudantes, embora exista resistência por parte de alguns deles, a receptividade positiva é relativamente alta.

Dessa maneira as tecnologias digitais na educação devem ser entendidas como uma aliada, auxiliando tanto o professor quanto os próprios estudantes na construção do saber. Assim, após a leitura das respostas obtidas dos discentes, de forma geral, é possível inferir que incluir as TDIC em sala de aula pode contribuir na compreensão dos conteúdos da Química, uma vez que se trabalha com representações, que por vezes são incompreensíveis para os estudantes. ${ }^{18}$

\section{Análise do questionário dos estudantes}

Considerando o questionário aplicado aos estudantes (Quadro 1) buscamos identificar as contribuições da SAI e se esta promoveu melhorias na forma como os discentes estudam. Inicialmente foi analisada como ocorreu à interação com as tecnologias digitais considerando as metodologias ativas, a partir dos pressupostos da aprendizagem tecnológica ativa ${ }^{4}$ e os posicionamentos dos discentes sobre a utilização das tecnologias digitais apropriadas pelo professor. Nesse momento o intuito foi de identificar se ocorreu alguma influência no desenvolvimento da turma e consequentemente na atuação do professor considerando suas práticas pedagógicas, flexibilizando assim o aprendizado, tornando mais versátil e dinâmica a forma como os discentes aprendem.

Em relação à disponibilização do vídeo pelo professor em um ambiente virtual, na turma $\mathrm{A}$, apenas onze discentes assistiram ao vídeo, enquanto todos os estudantes da turma $\mathrm{B}$ assistiram ao vídeo (pergunta 01). Nas respostas obtidas do questionário, dez estudantes da turma A e nove da turma B afirmaram que compreenderam o conteúdo de RMN de forma clara e objetiva (pergunta 02), apenas um estudante da turma $\mathrm{A}$ e quatro da turma B afirmaram que não compreenderam bem o conteúdo através do vídeo. Essa metodologia utilizada para tratar do conteúdo foi considerada promissora por todos os discentes da turma A e turma B, em que eles afirmam que a metodologia foi complementar ao assunto, uma vez que era possível eles realizarem pesquisas com o intuito de ampliar a compreensão do conteúdo.

A estratégia de utilizar o vídeo foi bastante aceita por partes dos estudantes por ser de fácil execução e acesso, além de poderem ver e rever o conteúdo no momento e local que desejem. Uma das respostas foi "O conteúdo foi dado de forma dinâmica e a resolução dos exercícios facilitou a aprendizagem" (A9), enquanto outro avalia da seguinte maneira "o assunto é teórico, então a metodologia na forma de vídeo contribuiu, além de poder voltar caso haja o surgimento de dúvidas" (B10).

Na turma A, onze estudantes afirmaram que o vídeo auxiliou na compreensão do conteúdo de RMN, uma vez que era um conteúdo que para eles tinha certo nível de complexidade, pois envolvia outros fatores da química que tornaram possível entender os espectros fornecidos nas imagens. Nesse contexto, para Moran ${ }^{19}$ os estudantes ao terem contato com o material previamente podem desenvolver suas habilidades referentes àquele conteúdo, já que tiveram contato também com outras informações e não apenas ao material fornecido pelo professor. Na turma B, a maioria dos estudantes (dez), afirmaram que a ferramenta utilizada é de fácil acesso, corroborando com as ideias de Bacich e Moran ${ }^{6}$ sobre a facilidade que as tecnologias trazem para o ambiente escolar, tanto para o professor quanto para o aluno em sua busca pelo aprendizado de forma independente.

Em contrapartida dois discentes Turma B disseram que a metodologia não contribuiu para tratar do assunto (pergunta 03), em que um afirma que "uma aula presencial é mais eficaz para tratar desse assunto" (B3), e outro que "em sala de aula pode-se tirar melhor as dúvidas que possam surgir acerca do conteúdo" (B9). Desse modo, podemos avaliar que a postura dos discentes, em sua maioria, foi favorável para a abordagem do assunto de RMN, por meio da SAI, considerando a estratégia adotada pelo professor.

Em relação às dúvidas que foram consultadas em sala de aula após a visualização do vídeo (pergunta 04), dois estudantes da turma A afirmaram que não conseguiram sanar suas dúvidas apenas com o vídeo, pois afirmam que "é necessário mais tempo de pesquisa e estudo a respeito" (A5), já nove discentes descreveram que conseguiram sanar suas dúvidas acerca do conteúdo. No que diz respeito à turma $\mathrm{B}$ todos os estudantes destacaram que conseguiram sanar suas dúvidas durante a visualização do vídeo. Os comentários por parte destes discentes destacavam que "o conteúdo era bastante complexo" (B1), mas que ao assistirem o vídeo eles consideram que melhoraram o seu entendimento sobre RMN, entre os comentários estão de que "a comunicação tornou-se mais dinâmica, já que houvese entendimento prévio" (B6) e que ao "antecipar o conteúdo a ser dado pelo professor fez com que tivesse a oportunidade de ver o conteúdo e formular meus questionamentos" (B12). Os estudantes comentaram que a estratégia da SAI para o conteúdo de RMN favoreceu para a introdução do conteúdo a ser discutido em sala de aula e que os ajudaram a "compreender melhor os aspectos dos espectros que eram disponibilizados no vídeo" (B3).

No que diz respeito a se os estudantes realizaram alguma pesquisa para complementar a aprendizagem do conteúdo (pergunta 05), cinco estudantes da turma A afirmaram que fizeram algum tipo de pesquisa complementar sobre o conteúdo, enquanto outros cinco não realizaram nenhum tipo de pesquisa, por acharem que o vídeo estava bem completo. Um dos estudantes comentou que "não foi necessário pesquisar com a explicação foi possível compreender" (A4). Já na turma B sete discentes afirmaram que fizeram algum tipo de pesquisa complementar sobre o conteúdo, seis não realizaram nenhum tipo de pesquisa, sendo que destes, cinco não fizeram pesquisas por acharem que o vídeo estava completo. Um dos estudantes afirmou que por falta de tempo não realizou essa pesquisa complementar, pois "por mais que o material seja suficiente, nunca é demais pesquisar" (B9).

É preciso destacar que para todos os estudantes (de ambas as turmas) o vídeo facilitou o debate e a realização de atividades (pergunta 06) em sala de aula. Como explicitado por $\operatorname{Moran}^{20}$ (p. 29) "a linguagem audiovisual desenvolve múltiplas atitudes perceptivas: solicita constantemente a imaginação e reinveste a afetividade com um papel de mediação primordial no mundo". O recurso do vídeo pode ser utilizado para aguçar os estudantes a respeito das várias temáticas na química, fazendo-os refletirem sobre o que se está sendo estudado, 
criando nestes um valor mais significativo para aquele conteúdo, além de os envolverem com o assunto de forma que os façam se questionar e procurar por mais explicações para os fenômenos mostrados, o que foi observado nas respostas. Segundo os estudantes, a visualização do conteúdo de forma prévia facilitou a sua compreensão, pois "vendo o assunto antes no vídeo, fica mais fácil de debater em sala" (A5). Dessa forma acreditamos que o processo de construção do conhecimento desses estudantes pode ter sido ampliado considerando o fato do discente já conhecer o conteúdo que será abordado em sala de aula. Segundo A11 a facilitação se deu na realização das atividades posteriores "Pois, ao realizar uma atividade proposta pelo professor foi mais fácil" (A11).

Sobre o questionamento se houve melhoria na dinâmica do professor (pergunta 07), na turma A apenas dois estudantes afirmaram que não, pois " a aula no vídeo foi bem parecida com a aula presencial" (A7) enquanto nove alunos consideram que ocorreu certa melhoria na forma como o professor expõe sua aula. Quando analisamos as respostas referentes à turma $\mathrm{B}$, todos os discentes asseveraram que houve uma melhoria na dinâmica do professor. Os discentes salientaram que a tecnologia auxiliou no aprendizado do conteúdo e que o professor ao fazer uso dessa estratégia aumentou o potencial de sua aula (consequentemente sua dinâmica). Para A3 " $A$ dinâmica de sala por vezes contrai [intimida] os estudantes, a partir de um recurso audiovisual, seguramente há maior dinamicidade". Nesse sentido, acreditamos que essa dinamicidade revela uma possível interação entre os estudantes e o professor através do uso dessa ferramenta. Já para B11 "é a primeira vez, que um professor de química aborda o assunto através desta ferramenta", indicando que a integração de tecnologias digitais nas aulas pode ser um importante recurso para a formação dos estudantes, uma vez que ao serem utilizadas favorecem que o professor e/ou discente tenham uma melhor experiência do conteúdo.

No que refere à pergunta 08 , todos os estudantes das duas turmas concordaram que a estratégia contribuiu significativamente, pois segundo eles "é um assunto complexo e me possibilitou a fazer pesquisas e tirar dúvidas posteriormente" (B6) e "foi interessante ver o vídeo e poder ir para a aula sabendo o que iria perguntar ao professor, me senti mais inteligente" (A8). Essa última fala demonstra a importância da atividade possibilitar que o estudante se aproprie do conteúdo, pois ao compreenderem o assunto (mesmo que uma parte dele), eleva sua autoestima, contribuindo para que o estudante se sinta parte do processo de construção do conhecimento, cooperando para uma aula mais participativa e ativa. ${ }^{1,4}$ Além disso, a atividade incentivou os estudantes a terem acesso a outros materiais antes da aula, tempo para estudarem e formularem suas dúvidas antes de participarem das discussões (debate) com o professor e com a turma. Segundo B10 a estratégia facilitou porque "demonstra um conteúdo que permite uso de imagens e representações, a visualização das representações químicas, facilita que a gente tenha um melhor significado do conteúdo abordado".

Os estudantes, em sua maioria, relataram que o vídeo facilitou a aprendizagem devido ao grau de complexidade do conteúdo e que através do material puderam ter uma base de como iriam estudar o conteúdo (RMN) e com a orientação do professor puderam tirar suas dúvidas durante o processo de construção de seu conhecimento em um espaço diferente da sala de aula, como proposto por Goudouris e Strucher. ${ }^{2}$ Ademais, os estudantes afirmaram que compreenderam o conteúdo de RMN ao utilizar o vídeo como um material de apoio e também guia, já que eles também procuraram outros textos, áudio etc. que facilitaram seu entendimento em relação ao conteúdo, como dito por Moran ${ }^{19}$ que as tecnologias auxiliam no desenvolvimento de suas capacidades de aprendizagem.

Quando questionados se aplicariam essa estratégia em sua prática docente (pergunta 09), apenas um estudante da turma A revelou que não aplicaria essa estratégia da sala de aula invertida, pois é preciso "levar em consideração a escola de nível médio e sua complexidade e alto nível de abstração da disciplina" (A7). Os demais estudantes dessa turma afirmaram que aplicariam essa estratégia em sua prática docente. Para eles o uso do vídeo na estratégia da SAI permitia a sua reprodução várias vezes (já que estava disponível na plataforma on-line), em que essas atividades auxiliavam no desenvolvimento da aprendizagem do estudante. Em relação à turma $\mathrm{B}$, uma estudante disse que não aplicaria essa estratégia em sua prática docente, pois é "adepta a outras ferramentas para o ensino" (B5), mas não informou que ferramentas seriam essas. Os doze estudantes disseram ser favoráveis à aplicação dessa estratégia em suas futuras práticas como professores. Esses estudantes, de forma geral, descreveram que o vídeo foi didático por apresentar sons do aparelho de RMN, ter explicação das imagens dos espectros, facilitando a compreensão dos mesmos acerca do que o professor iria aprofundar em sala de aula.

Essa abordagem do conteúdo de forma mais audiovisual chama a atenção do estudante e provoca seu interesse para o que está sendo mostrado, principalmente em termos de motivação para estudar. Ademais, alguns comentários das turmas coincidiram no que diz respeito de que a estratégia da SAI apresentava a possibilidade de ser replicada em vários momentos, que consegue envolver o estudante, sendo considerada uma boa estratégia por eles. Para A11 "é um instrumento a mais na metodologia impedindo que haja certa rotina nas aulas", "essa estratégia é útil para tirar de certa forma a monotonia das aulas" (B12) e que "não deixa o aluno passivo, esperando o professor escrever no quadro" (A2).

Sobre a contribuição das tecnologias para explicar os conteúdos de Química Orgânica (pergunta 10), na turma A três estudantes disseram que não acreditavam nessa contribuição, pois para eles "depende muito da forma que a tecnologia será aplicada $e$ assim poderá facilitar o ensino" (A10) e também "depende da complexidade do assunto" (A6). Os demais discentes descreveram que as tecnologias contribuíam para a explicação de todos os assuntos de química orgânica "porque além dos vídeos, temos vários programas que auxiliam no ensino de química" (A3). Leite ${ }^{3}$ alerta a necessidade de ter cuidado com essa visão de que as tecnologias serão "as salvadoras” do ensino de Química, elas vêm para contribuir no processo de ensino e aprendizagem e que se não forem inseridas através de estratégias didáticas, tendem a fracassarem. Na turma B, observamos que seis estudantes afirmaram que não, pois "é um método cabível para o ensino, porém não explica tudo" (B4), corroborando com as ideias de Leite. $^{3}$

É importante destacar que as estratégias tecnológicas experimentadas por grande parte dos estudantes em sala de aula são poucas, eles não conseguem de certa forma visualizar se a tecnologia contribuiria ou não para a explicação de mais assuntos de Química de uma forma geral, muitas vezes devido a essa limitação em sua formação. Para os que acreditam que as tecnologias podem ser utilizadas, destacamos uma fala ponderada do estudante B12 em que para ele "todos não, mas sua maioria dada à dificuldade dessa área de química". Podemos inferir que as dificuldades dos conteúdos em Química são inúmeras, pois cada estudante lida com uma maneira diferente de compreendê-los e querer que as tecnologias possam unicamente resolver todos os problemas do ensino de Química é, no mínimo, ingênuo. Os estudantes de certa maneira acreditam que a tecnologia pode auxiliar, porém não tem dimensão do que pode ser aplicado para que ela ajude. A utilização das tecnologias em sala de aula ainda é vista de forma bem cautelosa por alguns profissionais da educação, principalmente no que se referem às tecnologias que permitem que o estudante seja mais independente no sentido de buscar seu próprio conhecimento. Para futuros professores, as tecnologias 
devem estar atreladas a sua prática pedagógica, pois além de ser uma ferramenta útil, ela também é inerente a vida das pessoas atualmente.

De forma geral, em relação à inclusão das tecnologias nas aulas de química orgânica (pergunta 11), os estudantes indicaram que o professor deve se planejar com relação ao conteúdo que vai ser abordado para os seus estudantes e de que modo vai abordá-lo, refletindo sobre qual a ferramenta mais indicada para ser utilizada. Algumas respostas foram: "é preciso planejar, para que a aula não fuja do foco central do tema abordado" (A13); "o professor deve ter conhecimento da tecnologia que está querendo utilizar para deixar claro o seu objetivo e bem claro o assunto" (B1); "utilizá-las como ferramenta auxiliar no processo de ensino requer planejamento, pois tem potencial para contribuir em diversos conteúdos" (B12). $\mathrm{Na}$ prática pedagógica de alguns professores, observamos que a utilização das ferramentas tecnologias muitas vezes ocorre sem o devido planejamento, o que dificulta sua utilização. O professor deve planejar os recursos didáticos digitais que irá utilizar com sua turma, que conteúdos e objetivos devem ser alcançados com o uso dessas tecnologias.

Quando perguntados sobre a frequência da utilização de recursos didáticos digitais em sala de aula pelo professor (pergunta 12), a Figura 2 sintetiza as respostas obtidas.

Na pergunta que é relacionada ao emprego das tecnologias e sua facilitação para o professor (pergunta 13, item a), nas turmas A e B dezoito estudantes afirmaram que sim. Alguns justificaram que "a representação Química dos conteúdos vistos foi boa para uma melhor compreensão do conteúdo" (A13), que através dos recursos didáticos digitais "pode-se trazer imagens, exemplos e coisas interessantes para mostrar aos alunos" (A5) e que "é uma ótima ferramenta que facilita o processor de ensino-aprendizagem" (B6). Seis discentes responderam que talvez, uma das respostas explicava que "o desempenho do professor vai depender da forma como o mesmo faz uso das tecnologias" (B12) e outra que "não necessariamente o uso da tecnologia facilita, até porque há professores quem nem sabem fazer uso" (A7), corroborando com os pressupostos de Leite, ${ }^{3}$ que destaca que um dos problemas que são bem visíveis é a dificuldade que professores têm de fazer uso das TDIC.

Quando analisamos o item b da pergunta 13, dezesseis estudantes das duas turmas responderam que as tecnologias facilitam a aprendizagem do estudante e seu desempenho em sala de aula. Para eles as TDIC melhoram o entendimento e proporcionam uma maior interação dentro e fora de sala de aula, como descreve A8: "A interação aluno e tecnologia é algo nato, deve-se aprender a conviver com as tecnologias e não excluí-las". Para oito estudantes, a tecnologia talvez facilitasse um melhor desempenho e apresentaram distintos fatores envolvidos, um deles é que "o recurso a ser utilizado pelo professor e pelo próprio estudante pode talvez facilitar a aprendizagem" (B1) e que essa facilitação em aprender conteúdos através das TDIC irá depender da tecnologia a ser empregada, "[...] do momento em que for usada e da forma como foi aplicada" (A3).

\section{Análise da entrevista com o professor}

A utilização da entrevista estruturada (Quadro 2) tinha como objetivo compreender as percepções do professor da disciplina acerca da SAI. Assim, quando questionado pela forma como geralmente ministra suas aulas (pergunta 01), o docente destacou que "gosto de fazer uma dinâmica com os meus alunos de forma que eu garanta que eles consigam construir o conceito que eu estou querendo trabalhar". Essa resposta do professor corrobora com os pressupostos da aprendizagem tecnológica ativa que busca tornar o estudante autônomo com relação ao modo como relaciona o que aprende e como aprende, ${ }^{4}$ rompendo assim com o ensino exclusivamente expositivo, imutável, repetitivo e não pensante. Além disso, ao fazer uso das tecnologias digitais o professor espera que seus discentes possam obter algumas características que contribuam para sua aprendizagem, possibilitando que eles "evoluam no processo educacional"21 (p.146). Para Carvalho e Ivanoff ${ }^{21}$ ao desenvolver seu trabalho, o professor avalia as melhores alternativas e seleciona as TDIC mais apropriadas.

No que se refere às contribuições para a aprendizagem dos seus discentes (pergunta 02), o docente discorre que "às vezes só a gente falar ou desenhar no quadro não é suficiente, aí utilizar alguma ferramenta em auxilio, eu acho que ajuda". Embora o docente não indique que ferramentas podem auxiliar na aprendizagem dos estudantes, acreditamos que ao se utilizar ferramentas que estimulem o estudante a trabalhar em grupo, a ser mais ativo dentro e fora da sala de aula, que promova sua autonomia em relação ao seu aprendizado, pode ser um dos requisitos fundamentais para se inovar em sua prática docente, como enfatiza Costa, Dantas Filho e Moita, ${ }^{22}$ na qual "devemos buscar alternativas ao discurso do professor para motivar os discentes no aprendizado de Química para isso os docentes precisam explorar as relações dessa ciência com outras disciplinas e procurar metodologias que tenham a interação e a participação do aluno como ideia fundamental"'22 (p.32).

Quando questionado se a estratégia da SAI auxiliou na construção de conhecimento dos estudantes nas suas turmas (pergunta 03),

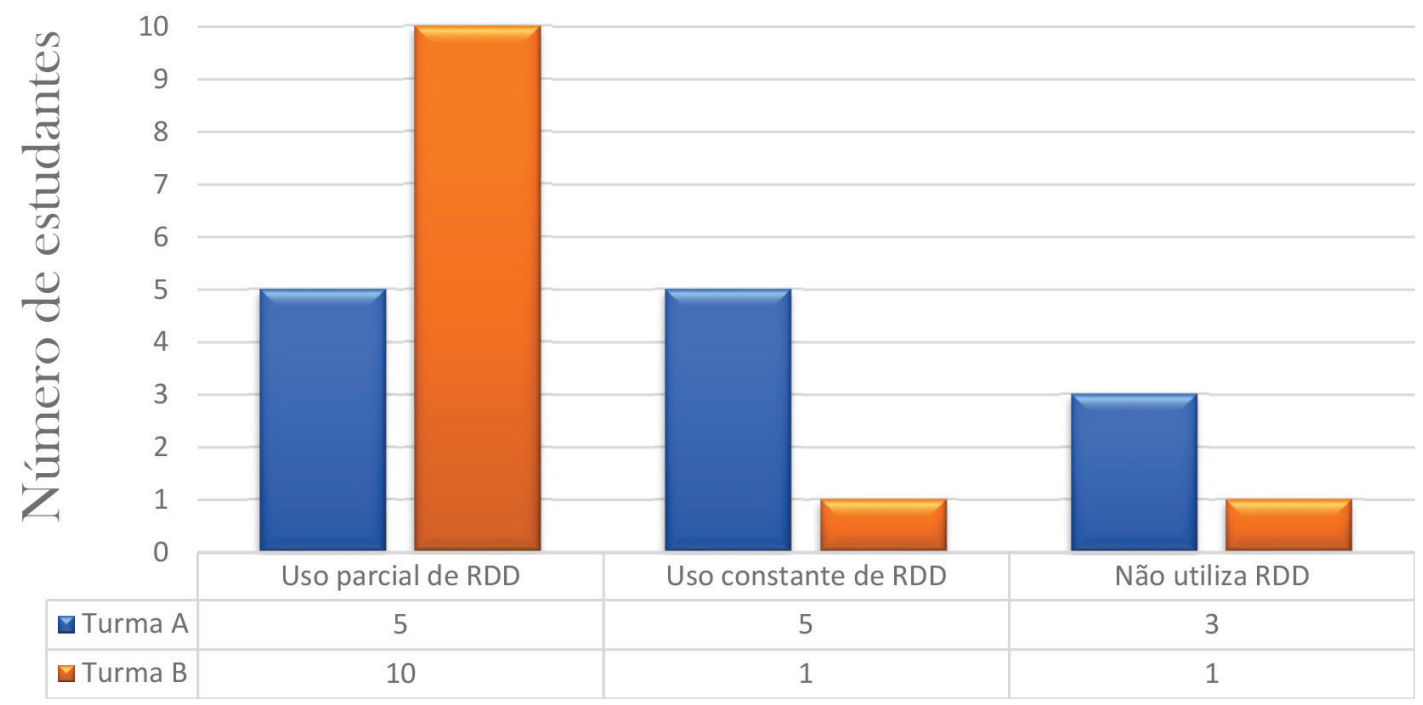

Figura 2. Relato dos estudantes em relação à frequência de uso dos $R D D$ 
o docente descreveu que as duas turmas tiveram momentos de aprendizagem diferentes, mas que isso não interferiu na forma como ambas contribuíram em sala de aula para aprofundar o conhecimento dos estudantes, isso pode ser observado em sua fala "foi proveitoso para os alunos porque tem um material que eles podem consultar constantemente". Nesse sentido, ao utilizar a SAI para explorar o conteúdo, o professor a considerou como uma estratégia significativa para seus estudantes, uma vez que esses já chegaram à sala de aula com uma base do que iria ser aprendido acerca do conteúdo de Ressonância Magnética Nuclear, "os meninos [Estudantes] já chegaram com ideias, perguntas, dúvidas, o que não é comum, achei bastante efetiva e significativa essa estratégia”.

A estratégia da SAI possui vantagens que são atreladas ao seu lado virtual e presencial, em que os estudantes têm mais tempo para estudar e variadas formas de como irão estudar (virtual), sendo que o professor considera "[...] que por eles terem visto meu vídeo e consultado mais materiais, é uma forma de construir o conhecimento". Para Souza, ${ }^{23}$ a integração efetiva destes dois ambientes de aprendizagem será realmente efetiva quando se levar em consideração as peculiaridades da dimensão educacional e é aprofundado quando realizado em sala de aula (presencial) junto aos colegas de classe e o professor.

Em relação à pergunta 04 (Qual das turmas você acredita que a estratégia foi mais efetiva? Por quê?), o docente afirmou que nenhuma das turmas teve uma diferença na aprendizagem de forma muito significativa, ressaltando que "[eu] apliquei em uma turma no início do curso e em outra turma no final da disciplina e a experiência foi parecida". Esta fala reforça a ideia de se aplicar a SAI em momentos distintos durante uma disciplina (conteúdo, aula etc.), o que permite que o professor possa traçar estratégias para aplicação desta metodologia em diversos contextos.

Destarte, as variações em relação à utilização da sala de aula invertida (pergunta 05) na forma em que os estudantes aprenderam não foram consideradas muito diferentes pelo docente. Para ele, os discentes tiveram acesso a vários meios de comunicação para interagir e assim contribuir com sua aprendizagem e com a dos outros através de discussões que foram realizadas on-line, em grupos, chats etc.

Ademais, o professor ponderou que a colaboração ocorrida em sala de aula foi enriquecida com os questionamentos feitos pelos discentes, evidenciando uma aprendizagem colaborativa, conforme um dos pilares da aprendizagem tecnológica ativa. ${ }^{1,4}$ Embora tentasse descrever que nenhuma diferença tenha sido notada por ele (professor) sua fala infere que uma das turmas teve um pouco mais de atenção no que se refere ao utilizar o material disponibilizado, conforme transcrito " a segunda turma que eu apliquei no início do curso, a maior parte dos alunos, assistiram e até se prepararam um pouco mais no assunto".

Para Almeida, ${ }^{24}$ o professor ao compartilhar materiais com os estudantes e ao utilizar plataformas digitais que permitem uma comunicação fora da sala de aula com seus estudantes, possibilita relações mais próximas como consequência da utilização dessas TDIC. Nesse contexto, o comportamento dos estudantes (pergunta 06) para o docente não houve diferença na dinâmica de comunicação em sala de aula e ambientes virtuais, isso pode ser observado na afirmação: "a dinâmica foi bem similar à como se eu tivesse trabalhado na aula anterior".

Na sua avaliação do uso da metodologia do EH (pergunta 07), o professor compreende que esse método o deixa "mais livre para em sala de aula para aprofundar um pouco mais os conteúdos". De fato, essa é uma das características do EH, pois ao utilizar as tecnologias digitais o professor pode se tornar mais versátil, modificando a forma a qual irá disponibilizar materiais de apoio para que o discente estude, bem como irá promover uma maior independência do estudante (pilar da aprendizagem tecnológica ativa), incentivando-o a aprofundar o conhecimento, tendo um suporte dado pelo próprio professor.
No que diz respeito à pergunta 08 , o docente considerou benéfico para os estudantes, pois "flexibilizou a forma como os alunos estudariam, considerando o tempo de cada um". Além disso, o professor afirmou que os estudantes "iriam aprender ainda mais sobre o conteúdo com o material que fiz" e que uma das vantagens foi à falta de tempo específico para se explorar o assunto de RMN, que segundo o docente "requer bastante atenção de minha parte, por ser necessário explorar bastantes conceitos da Química", uma vez que em sala de aula, de forma presencial "cada professor tem um tempo específico para abordar os conteúdos". Por fim, o professor afirma que conseguiu trabalhar o que considera mais importante no conteúdo de RMN para ser mostrado através do vídeo, em que "aquela aula que eu gravei, eu trabalhei todos os pontos que eu achei cruciais".

Em relação à avaliação geral sobre a atividade (pergunta 09) feita com os estudantes, o professor afirmou que "deu uma boa base para dar andamento com o conteúdo". O docente destacou que "estava bastante esclarecido sobre a utilização e como funcionavam os recursos [na sala de aula invertida]" e que esse conhecimento sobre como proceder iria proporcionar uma "abordagem mais efetiva para minhas aulas e para a compreensão do conteúdo pelos alunos".

Quando solicitado para sugerir ou comentar algo sobre a prática realizada (pergunta 10), o docente destacou que as "tecnologias [digitais] possuem uma variedade de possibilidades para adequar o conteúdo a ser visto pelos alunos com um recurso tecnológico que vá atender as necessidades dos mesmos" e que "acho que ela [tecnologia] pode ser aplicada em outros temas em outras disciplinas no nosso curso", demonstrando que há possibilidades para que essa estratégia seja utilizada em outros conteúdos da Química. Entretanto, um obstáculo observado para a inserção dessas estratégias está no uso da tecnologia como um recurso acessível e viável em sala de aula, em que alguns casos não há preparo por parte do professor. Entendemos que cada docente possui uma estratégia diferente para conseguir que suas aulas sejam compreensíveis aos seus estudantes e que a utilização das TDIC como auxiliadora possibilita que ocorra maior interação entre os estudantes, entre estudante-professor e com o material que estão sendo abordados.

\section{CONCLUSÕES}

Nesta pesquisa apresentamos a aplicação da sala de aula invertida, um dos tipos de ensino híbrido, em duas turmas do curso de licenciatura em Química na disciplina de Química Orgânica C. Consideramos que essa metodologia ativa pode ser considerada uma alternativa viável para contribuir para o processo de ensino e aprendizagem da Química Orgânica. Por meio da SAI, o professor participante relatou que foi possível aprofundar o conteúdo de RMN com seus estudantes, além de ministrar sua aula de forma diferente das quais ele estava habituado, focando nas dúvidas individuais dos estudantes, como também nos comentários feitos acerca do vídeo que foi utilizado para introduzir o conteúdo.

É importante destacar que na proposta da SAI para o ensino de Química Orgânica, especificamente RMN, os estudantes tiveram controle sobre o espaço (local) e tempo que iriam estudar, além de terem apresentado um compromisso em relação a sua própria aprendizagem. Com isso, aponta-se que as tecnologias digitais podem contribuir no processo de ensino e aprendizagem e o professor ao fazer uso delas, como um recurso didático digital para a aprendizagem de seus discentes, consegue transformar não só o ambiente de sala de aula, mas a forma como os estudantes enxergam e constroem sua própria aprendizagem.

Em relação ao professor da disciplina destaca-se sua contribuição como mediador/facilitador desde a condução da aplicação da SAI, como na elaboração dos materiais suplementares e na realização das 
atividades. O professor teve papel significativo em todo o processo, além de se comprometer com a utilização de uma metodologia diferente da que ele realizava em sua prática pedagógica, se mostrando aberto a novas possibilidades.

O momento de discussão em sala de aula proporcionou aos discentes uma oportunidade de ter um maior envolvimento e comprometimento com a sua própria aprendizagem. Eles puderam (re)ver a forma como estão acostumados a aprenderem e como a utilização dos recursos didáticos digitais pode abordar determinado conteúdo em sala de aula. Ademais, pôde-se dar autonomia para que o estudante se sentisse a vontade para decidir como e quando queria aprender, e para que ele tivesse uma melhor compreensão, mais de um recurso foi utilizado, garantindo que os estudantes não se sentissem "presos" a uma única forma de aprender.

Por fim, nessa pesquisa sobre uma das estratégias do ensino híbrido foi possível identificar em sua aplicação, para o nosso caso, que a SAI contribuiu para o processo de ensino e aprendizagem do conteúdo de RMN, facilitando o desempenho dos estudantes e auxiliando o professor em sua prática pedagógica. A estratégia (da SAI), ao ser aplicada, mostrou que a dinâmica da sala de aula (física) sofreu mudanças, em que os estudantes se mostram ávidos em participar e abertos a também utilizarem em suas futuras práticas docentes.

A SAI é uma das opções de metodologias ativas a ser utilizada pelos docentes, principalmente por mostrar que sua aplicação não é complexa, mas precisa acima de tudo do planejamento do docente para que ocorra de forma favorável. Através das respostas do professor e dos estudantes se percebe que a estratégia utilizada não era bem conhecida, e que por meio dessa aplicação os mesmos passaram a se interessar pela proposta, contribuindo assim para que esses futuros docentes pensem sobre a inclusão da SAI em suas práxis. Considera-se que essa pesquisa apresenta uma experiência que pode ser replicada por outros docentes e que façam uso da SAI em suas práticas pedagógicas, de modo a contribuir para a construção do conhecimento de seus estudantes.

\section{AGRADECIMENTOS}

Ao PIC/UFRPE, LEUTEQ e ao professor T. R. C. L. Souza no desenvolvimento da pesquisa.

\section{REFERÊNCIAS}

1. Leite, B. S.; Pesquisa e Ensino 2020, 1, e202012.

2. Goudouris, E.; Struchiner, M.; Rev. Bras. Educ. Med. 2015, 39, 620.

3. Leite, B. S.; Tecnologias no Ensino de Química: teoria e prática na formação docente, $1^{\mathrm{a}}$ ed. Appris: Curitiba, 2015.

4. Leite, B. S.; Revista Internacional de Educação Superior 2018, 4, 580.

5. Leite, B. S.; Revista Brasileira de Ensino de Ciência e Tecnologia 2017, 10, 206.

6. Bacich, L.; Moran, J.; Revista Pátio 2015, 25, 45.

7. Moran, J. Em Metodologias ativas para uma educação inovadora: teórico-prática; Moran, J., Bacich, L., eds.; Penso: Porto Alegre, 2018.

8. Berbel, N. A. N.; Semina: Ciênc. Soc. Hum. 2011, 32, 25.

9. Bacich, L.; Tanzi Neto, A.; Trevisani, F.; Ensino Híbrido: personalização e tecnologias na educação, Penso: Porto Alegre, 2015.

10. Castro, A. B. B.; Mill, D.; Revista Diálogo Internacional 2018, 18, p. 760.

11. Horn, M. B.; Staker, H.; Christensen, C.; Blended: usando a inovação disruptiva para aprimorar a educação, $1^{\mathrm{a}}$ ed., Penso: Porto Alegre, 2015.

12. Moran, J.; Educatrix 2014, 52.

13. Holloway, I.; Wheller, S.; Nursing Ethics 1995, 2, 223.

14. Rodrigues, R. M.; Pesquisa acadêmica: como facilitar o processo de preparação de suas etapas, $1^{\mathrm{a}}$ ed. Atlas: São Paulo, 2007.

15. Lüdke, M.; André, M. E. D. A.; Pesquisa em educação: Abordagens Qualitativas, E. P. U.: São Paulo, 2012.

16. Marconi, M. A.; Lakatos, M.; Técnicas de Pesquisa, $8^{\mathrm{a}}$ ed., Atlas: São Paulo, 2017.

17. Ferrari, A. T.; Metodologia da ciência, $2^{\mathrm{a}}$ ed., Kennedy: Rio de Janeiro, 1974.

18. Souza, J. I. R.; Leite, Q. S. S.; Leite, B. S.; Revista Docência do Ensino Superior 2015, 5, 135.

19. Moran, J. Em Ensino Híbrido: personalização e tecnologia na educação; Bacich, L., Neto, A. T., Trevisani, F., eds. Penso: Porto Alegre, 2015.

20. Moran, J.; Comunicação \& Educação 1995, 27.

21. Carvalho, F. C. A.; Ivanoff, G. B.; Tecnologias que educam: ensinar e aprender com as tecnologias de informação e comunicação, $1^{\mathrm{a}} \mathrm{ed}$., Pearson Prentice Hall: São Paulo, 2009.

22. Costa, C. H. C.; Dantas Filho, F. F.; Moita, F. M. G. S. C. Holos 2017, 1,31 .

23. Souza, F. N. Em Tecnologias na Educação: uma abordagem crítica para uma atuação prática; Leão, M. B. C. $1^{a}$ ed. UFRPE: Recife, 2011.

24. Almeida, P.; Da Investigação às Práticas 2018, 8, 4. 